\title{
Fabrication and Characterization of Graphene Oxide Doped SU-8 Polymer Waveguide
}

\author{
Mohd Haniff Ibrahim*, Mohd Rashidi Salim, Muhammad Yusof Mohd Noor and Norazan Mohd Kassim \\ School of Electrical Engineering, Faculty of Engineering, UniversitiTeknologi Malaysia, \\ 81310 UTM Skudai, Johor, Malaysia.
}

*Corresponding author: hanif@fke.utm.my, Tel: +607-5557194, Fax: +607-5566272

\begin{abstract}
In this paper, graphene oxide (GO) was doped into SU-8 polymer to examine the functionalities of polymer waveguide material via dopant inclusion. In material preparation, step by step processes starting from cyclopentanone mixing will be explained. It is shown that doped material's refractive index can be tailored by having different weight percentage of GO. Finally, a single mode ridge waveguide loss of GO doped SU-8 has been characterized to be $1.9 \mathrm{~dB} / \mathrm{cm}$ at $1550 \mathrm{~nm}$ wavelength.
\end{abstract}

Keywords: Cyclopentanone mixing, Dopant inclusion, Graphene oxide, SU-8 polymer

(C) 2018 Penerbit UTM Press. All rights reserved

\section{INTRODUCTION}

Fabrication of waveguide plays an important role in making sure that the developed waveguide meets the criteria needed for certain applications. There are several factors that need to be taken into consideration before selecting materials for fabrication of waveguides.

There are two common types of fabrication technique in waveguide which are dry and wet etching. Selection of fabrication technique mainly depends on material and also structure of developed channel. Waveguide fabrication using glass-based and semiconductor materials is not cost effective, as compared with polymer material. Our previous work on photodefinable polymer had proven the cost-effectiveness argument [1-3]. Meanwhile, SU-8 polymer had been attracting extensive interest from researcher due to its negative photoresist properties, low cost and high aspect ratio [4]. Due to the use of SU-8 polymer as the waveguide material in this work, a wet etching technique was used in addition to its low cost and simple in preparation as compared to dry etching [5].

In addition, there is not much work on functionalities of SU-8 polymer waveguide via dopant inclusion. Graphene had been a topic of interest and various studies such as graphene based composites, graphene-based nanoparticles and graphene-based coating have been applied in various applications such as light emitting diode, photovoltaic devices, touch screen and broadband polarizer [6]. Motivated by great advantages offered by these two sets of material, further investigation need to be done. Therefore, this work is steered on experimenting a new doped material consisting of graphene and SU-8 polymer that will be further characterized to investigate its functionalities in optical waveguiding application.

One of the derivative of graphene is Graphene Oxide
(GO) which is a nano material having $\mathrm{sp}^{2}$ and $\mathrm{sp}^{3}$ hybridisation honeycomb structure. Interestingly, GO exhibits hydrophilic properties which makes it easily dispersible in water or organic solvent [7]. As for this, a modified Hummer's method [8] is implemented, which uses shorter oxidation duration and lower temperature. Interested readers may refer to [9], on detailed processes of modified Hummer's method.

\section{METHODOLOGY}

In order to avoid a non-homogeneous mixture of GO and SU-8, a special SU-8 solvent of cyclopentanone is firstly mixed with the GO. In our work, few different concentrations of GO doped SU-8 polymer were prepared. These concentrations were depending on the prepared weight percentage of GO. For instance, in preparing for 0.030 wt. $\%$, it requires $3.5 \mathrm{mg}$ dried GO flakes to be scratched and mixed with $10 \mathrm{~m} \ell$ of cyclopentanone. This mixture is ultrasonicated for 10 minutes. $1.5 \mathrm{ml}$ of this homogeneous mixture was then mixed with $1.5 \mathrm{~m} \ell$ of SU82010 using ultrasonic bath for 20 minutes. Different concentration of GO doped SU- 8 were obtained by simply varying the weight of $\mathrm{GO}$ flakes.

Out of these tested concentrations, it has been observed that $0.055 \mathrm{wt}$. $\%$ of GO produced a darken mixture whereas other concentrations produce a semi-transparent mixture solution. It was noticed that other concentrations (which is below $0.055 \mathrm{wt}$. \%) produced a homogenous mixture when mixed with cyclopentanone, while solution with concentration of $0.055 \mathrm{wt}$. $\%$ is too dark and we were uncertain whether precipitation of GO occurs. Therefore, we have limit the $\mathrm{GO}$ concentration to $0.035 \mathrm{wt}$. \% to avoid further error in material characterization.

For refractive index and thickness characterization, the 
doped solutions were spun coated on glass substrate and went through our fabrication recipes which have been experimented and tested for its reliability. The recipes include softbake process, UV exposure and postbake exposure with determined period. By using a prism coupler, a graph of measured refractive index against GO concentration was obtained and shown in Figure 1.

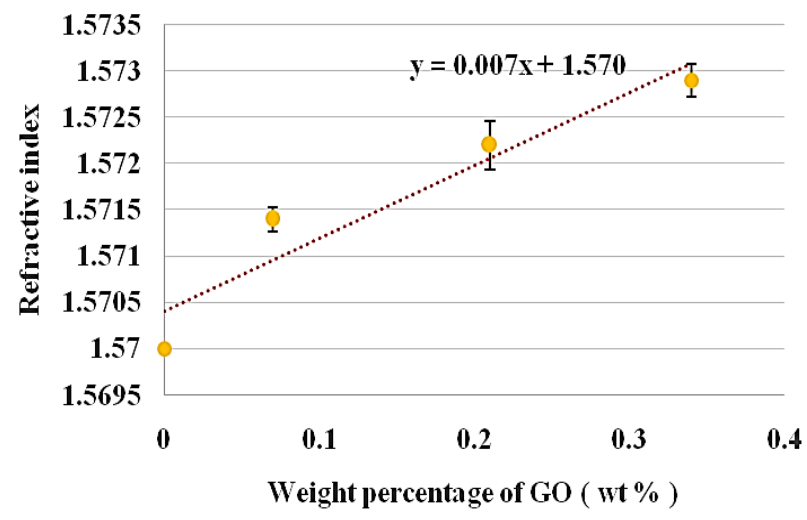

Figure 1. Refractive index with different GO concentration at $1550 \mathrm{~nm}$

\section{RESULTS AND DISCUSSION}

Based on Fig. 1, the refractive index of pure SU-8 polymer is 1.570. Interestingly, the refractive index of GO doped SU- 8 can be tailored accordingly by varying the GO concentration. For channel waveguide fabrication of this doped material, we adopted a refractive index of 1.5729 with respect to $0.035 \mathrm{wt}$. \% of GO concentration.

The process for the fabrication of channel waveguide using GO doped SU-8 polymer is similar to a thin film multi-chip module process. Based on our simulation, to produce a single mode waveguide, the core thickness needs to be at $1.6 \mu \mathrm{m}$. The homogeneous solution which was prepared earlier was spun on the substrate at $4000 \mathrm{rpm}$ for 1 minute. Note that the substrate used is a silicon wafer with $7 \mu \mathrm{m}$ thickness of silicon dioxide. Prior to the spin coating process, the wafer was rinsed in $\mathrm{H}_{2} \mathrm{SO}_{4}$ for 5 seconds and washed away using de-ionized water for 40 seconds.

The spun sample was then hot-plated at $95^{\circ} \mathrm{C}$ for 3 minutes. This is followed by photolithography step where the sample was exposed to UV lamp for 8 seconds. The chemical etching is then took place where an SU-8 developer solvent was dispensed onto the sample surface. The sample was then rinsed for 10 seconds and spun at high speed to remove residual solvent. Finally, the sample was placed on the hotplate for 3 hours at $80^{\circ} \mathrm{C}$ to harden the developed channel.

In order to characterize for a waveguide loss, a conventional cutback method has been adopted in the loss measurement. A single mode fiber is used to couple 1550 $\mathrm{nm}$ laser source into the end facet of the fabricated waveguide. The mode confinement is imaged onto an infrared camera. Figure 2 shows the image of output beam with $1550 \mathrm{~nm}$ laser coupled at the waveguide input.

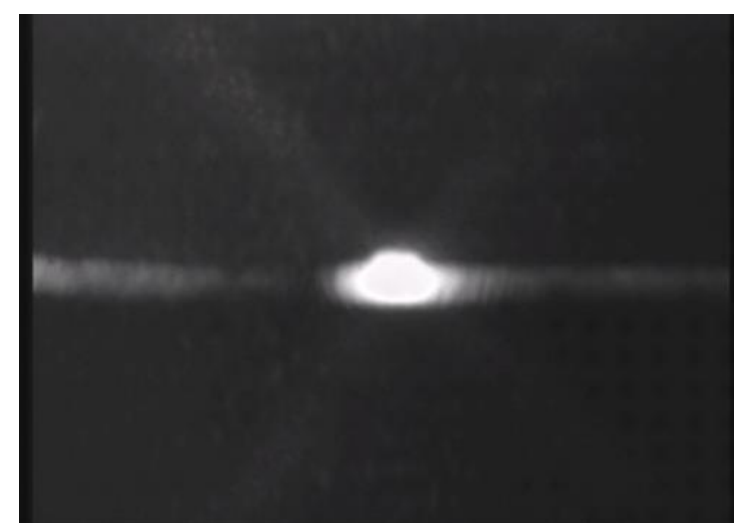

Figure 2.Single mode confinement using $1550 \mathrm{~nm}$ wavelength light source

The results of a cutback loss measurement performed on GO doped SU-8 optical waveguides are shown in Figure 3 . The slope of the line indicates that the propagation loss in the waveguides is $1.9 \mathrm{~dB} / \mathrm{cm}$ and the coupling loss is 4 $\mathrm{dB}$. The propagation loss achieved is acceptable when compared with works done by D. Zhang et al. [10] which also used doped SU-8 polymer but with different dopant material. Their work also managed to obtain $1.9 \mathrm{~dB} / \mathrm{cm}$ propagation loss. The high value of coupling loss is mainly due to the size mismatch between the fiber and the waveguide modes. With the measured loss of $1.9 \mathrm{~dB} / \mathrm{cm}$, the GO doped SU-8 polymer waveguides are suitable and competitive to be used for relatively short optical interconnect applications.

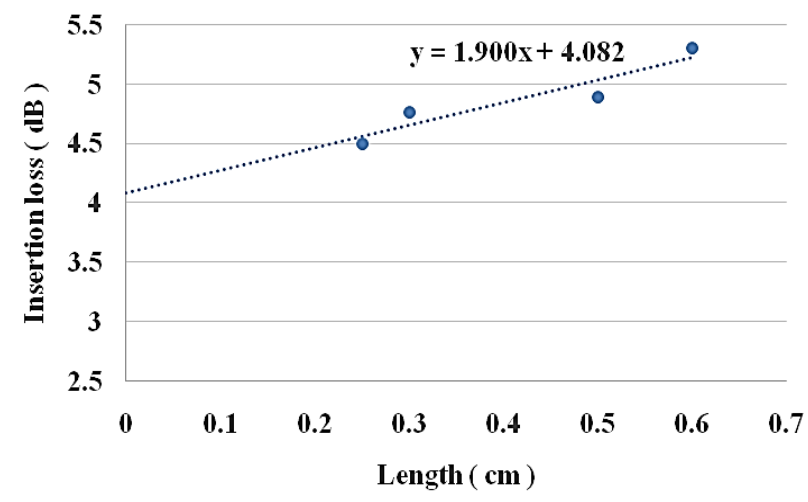

Figure 3. Results of cut-back method for developed waveguide

\section{CONCLUSION}

In conclusion, we have successfully demonstrated a mixing process of $\mathrm{GO}$ and $\mathrm{SU}-8$ polymer for possible application in optoelectronics. The new doped material can be controlled in terms of its refractive index by simply varying the weight percentage of GO. The doped material has been fabricated as a channel waveguide, utilizing silicon wafer with silicon dioxide as the underclad. The photolithography and chemical etching technique were utilized throughout the fabrication process, without the need for costly dry etching technique. For single mode application, a core dimension of $1.6 \mu \mathrm{m}$ was fabricated which is further characterized for loss using the cutback method. A comparatively small propagation loss of 1.9 
$\mathrm{dB} / \mathrm{cm}$ at $1550 \mathrm{~nm}$ was recorded. This new doped material of GO and SU-8 is suitable to be used for relatively short photonic devices and economically saved in terms of realization cost.

\section{ACKNOWLEDGMENT}

The authors wish to thank UniversitiTeknologi Malaysia and Ministry of Higher Education Malaysia, for funding this work.

\section{REFERENCES}

[1] M.H. Ibrahim, N.M. Kassim, A.B. Mohamad, A.S.M. Supa'at, S.Y. Lee and M.K. Chin. "Optical cross coupler based on wet-etch processing of Benzocyclobutene polymer". Optical Materials. 32: 703-706, 2010.

[2] M.H. Ibrahim, S.Y. Lee, M.K. Chin, N.M. Kassim and A.B. Mohamad. "Multimode interference optical splitter based on photodefinable Benzocyclobutene (BCB 4024-40) polymer". Optical Engineering. 46: $013401,2007$.

[3] Ibrahim, M. H., Shuh-Ying Lee, Mee-Koy Chin, N. Mohd Kassim, and A. B. Mohammad. "Single mode optical waveguides based on photodefinable benzocyclobutene

(BCB 4024-40) polymer". Microwave and Optical Technology Letters. 49:479-481, 2007.

[4] H. Lorenz, M. Despont, N. Fahrni, N. LaBianca, P. Renaud and P. Vettiger. "SU-8: A low-cost negative resist for MEMS" Journal of Micromechanics and Microengineering. 7:121-124, 1997.

[5] A. Grosse, M. Grewe, and H. Fouckhardt. "Deep wet etching of fused silica glass for hollow capillary optical leaky waveguides in microfluidic devices". Journal of Micromechanics and Microengineering. 11:257-262, 2001.

[6] Q. Bao, et al. "Broadband graphene polariser". Nature Photonics. 5:411-415, 2011.

[7] Y. Si, and E.T. Samulski. "Synthesis of water soluble graphene". Nano Letters. 8:1679-1682, 2008.

[8] D.C. Marcano, et al. "Improve synthesis of graphene oxide". ACS Nano 4:4806-4814, 2010.

[9] N.M. Huang, H.N. Lim, C.H. Chia, M.A. Yarmo and M.R. Muhamad. "Simple room-temperature preparation of high-yield large-area graphene oxide". Internationa Journal of Nanomedicine. 6:3443-3448, 2011.

[10]D. Zhang, X. Li, X. Huang, S. Liu, H. Fu, K. Che, and L. Wang. "Optical amplification at $1064 \mathrm{~nm}$ in Nd(TTA)3(TPPO)2 complex doped SU-8 polymer waveguide", IEEE Photonics Journal, 7: 1400607, 2015 . 